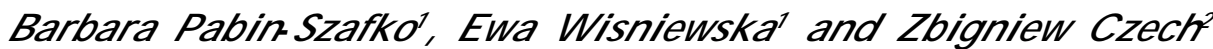

\section{SELECTED RADICAL AZOINITIATORS IN THE SYNTHESIS OF SOLVENT-BORNE ACRYLIC PRESSURE-SENSITIVE ADHESIVES}

\author{
${ }^{1}$ Polymer Institute, Szczecin University of Technology, 10 Pulaskiego, 70-322 Szczecin, Poland \\ pabinszafko@ps.pl \\ ${ }^{2}$ Department of Chemical Organic Technology, Szczecin University of Technology, 10 Pulaskiego, \\ 70-322 Szczecin, Poland
}

Received: February 13, 2009

() Pabin-Szafko B., Wisniewska E., Czech Z. 2009

\begin{abstract}
Functional azoinitiators: 2,2' -azobis(2-methyl4-hydroxybutyl propionate) (AIB-BD), 2,2'-azobis[2methyl- $\omega$-hydroxy-tri(oxyethylene) propionate] [AIBTri(OE)] and 2,2'-azobis[2-methyl- $\omega$-hydroxyoligo(oxyethylene) propionate] [AIB-OOE(400)] were used in radical polymerization of 2-ethylhexyl acrylate, methyl acrylate and acrylic acid in organic solvent ethyl acetate to prepare solvent-borne acrylic pressure-sensitive adhesives (PSA). After polymerization the viscosity, molecular weight and polydispersity of received acrylic PSA have been evaluated and compared with the product of polymerization initiated by the conventional azoinitiator 2,2'-azobisisobutyronitrile (AIBN).
\end{abstract}

Keywords: functional azoinitiators, acrylic monomers, radical polymerization, acrylic PSA.

\section{Introduction}

Pressure-sensitive adhesives (PSA) present an interesting class of products that offers the potential to produce self-adhesive products with a number of excellent properties such as tack, peel adhesion and shear strength. The term "pressure-sensitive" describes adhesives which in the "dry" form are permanently tacky at a room temperature and firmly adhere to a variety of widely different surfaces upon mere contact without the need of more than finger or hand pressure [1].

The first commercial PSA were derived from a natural rubber, which, along with various synthetic elastomers, is still one of the principal polymeric constituents. Shortly after World War II copolymers based on acrylics were introduced into the PSA market. They are used in self-adhesive tapes, labels and protective films as well as in dermal dosage systems for pharmaceutical applications, in biomedical electrodes, and in the assembly of automotive parts, toys, electronic circuits and keyboards [2].
The three common today basic types of acrylics are solvent-borne, water-borne and solvent-free acrylic PSA (Fig. 1) [3]. In the modern extensive field of pressuresensitive adhesives the solvent-borne acrylic PSA are more popular.

Acrylates and other suitable monomers are copolymerized to yield acrylic copolymers of specific compositions. Acrylics can be synthesized in an organic solvent. In this case, no further formulation is generally needed, although it is done from time to time to fine-tune the properties. The versatility of acrylic chemistry is useful in the design of high performance pressure-sensitive adhesives. The design parameters utilized to produce high performance solvent-borne adhesives include: kinds of monomers and their composition, nature of solvent, polymerization method, type and amount of initiator [4].

The acrylic monomers are commonly polymerized utilizing a free radical polymerization process involving the unsaturated bonds present in their structure. The free radical polymerization starts with an initiation step, where an initiator decomposes into radicals under the reaction conditions. These primary radicals are added to carboncarbon double bonds of the monomer resulting in propagating radicals that in its turn propagate further. Besides starting the process, the initiator used can influence the polymer structure. For instance, the peroxides tend to cause a hydrogen abstraction resulting in a higher degree of branching in the polymer, while the azoinitiators tend to yield linear polymers $[5,6]$.

The search of new methods of polymerization by a radical mechanism, and also catalytic systems, including new azoinitiators, the properties of which exceed the commonly used 2,2'-azobisisobutyronitrile (AIBN) is still actual [7-9]. The azoinitiators, differing from AIBN with their chemical structure (a lack of nitrile groups), undergo a thermal decomposition without toxic compounds release, as it occurs in the case of AIBN $[9,10]$. Therefore they can also be applied in biological systems [11]. They are a 


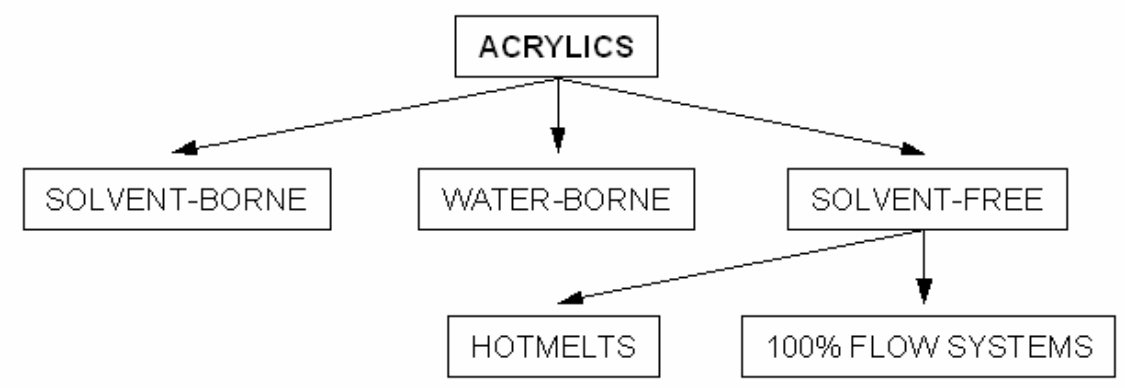

Fig. 1. Kinds of acrylic pressure-sensitive adhesives

Characteristics of diols and prepared azoesters

Table 1

\begin{tabular}{|c|c|c|c|c|c|c|c|}
\hline Diols & \multicolumn{2}{|c|}{$\begin{array}{c}\mathbf{M}_{\mathrm{diol}} \\
\text { acc. } \text { producer }\end{array}$} & \multicolumn{2}{|c|}{$\begin{array}{c}\overline{\mathrm{M}}_{\mathrm{n}} \\
\mathrm{VPO}^{\mathrm{a})}\end{array}$} & \multicolumn{3}{|c|}{$x(\mathrm{OH})^{b}$} \\
\hline $1,4-\mathrm{BD}$ & \multicolumn{2}{|c|}{90.05} & \multicolumn{2}{|c|}{-} & \multicolumn{3}{|c|}{-} \\
\hline Tri(OE) & \multicolumn{2}{|c|}{150.17} & \multicolumn{2}{|c|}{152} & \multicolumn{3}{|c|}{1.91} \\
\hline OOE(400) & \multicolumn{2}{|c|}{400} & \multicolumn{2}{|c|}{427} & \multicolumn{3}{|c|}{2.00} \\
\hline \multirow{2}{*}{ Azoinitiators } & molar ratio & $\overline{\mathrm{M}}_{\mathrm{n}}$ & $\overline{\mathrm{M}}_{\mathrm{n}}$ & $\overline{\mathrm{M}}_{\mathrm{w}}$ & \multirow{2}{*}{$\mathrm{x}(\mathrm{OH})$} & \multirow{2}{*}{$\begin{array}{l}\mathrm{W} \\
\%\end{array}$} & \multirow{2}{*}{$\mathrm{T}_{\mathrm{d} \max }{ }^{\mathrm{e})}$} \\
\hline & diol : AIBN & $\mathrm{VPO}^{\mathrm{a})}$ & \multicolumn{2}{|c|}{$\mathrm{GPC}^{\mathrm{c})}$} & & & \\
\hline AIB-BD & $10: 1$ & 334 & 380 & 471 & 2.02 & 84.3 & 130 \\
\hline AIB-Tri(OE) & $10: 1$ & 448 & - & - & 1.82 & 81.9 & 128 \\
\hline AIB-OOE(400) & $4: 1$ & 1117 & 1140 & 2190 & $2^{d)}$ & 88.0 & 133 \\
\hline
\end{tabular}

a) vapor pressure osmometer (VPO) Knauer-A0280 (solvent-toluene);

b) amount of $\mathrm{OH}$ groups in the molecule determined by a titration method according to PN-93/C-89052.03;

${ }^{c}$ ) the Waters GPC system with a refractive index detector (solvent - tetrahydrofurane);

d) amount of $\mathrm{OH}$ groups in the molecule determined on the basis of ${ }^{1} \mathrm{H}$ NMR spectra [14];

e) temperature of the N-C bond decomposition determined by DSC method (Perkin-Elmer DSC7), heating rate of $20 \% \mathrm{~min}$.<smiles>CC(C)(C#N)N=NC(C)(C)C#N</smiles>

AIBN<smiles>CC(C)(C)N=NC(C)(C)C(=O)OCCOCCO</smiles>

AIB-BD

$$
\begin{gathered}
\mathrm{HO}-\left[\mathrm{CH}_{2}-\mathrm{CH}_{2}-\mathrm{O}\right]_{3}-\mathrm{CO} \quad \mathrm{OC}-\mathrm{O}-\left[\mathrm{CH}_{2}-\mathrm{CH}_{2}-\mathrm{O}\right]_{3}-\mathrm{H} \\
\mathrm{H}_{3} \mathrm{C}-\mathrm{C}-\mathrm{N}=\mathrm{N}-\mathrm{C}-\mathrm{CH}_{3} \\
{ }_{\mathrm{CH}} \quad \mathrm{CH}_{3} \\
\text { AlB-Tri(OE) }
\end{gathered}
$$

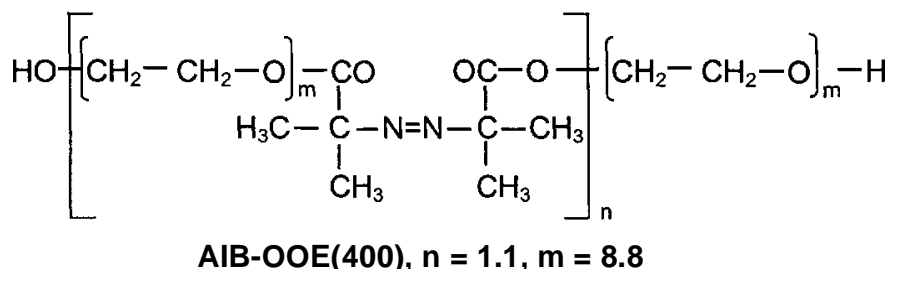

Fig. 2. Chemical formulas of AIBN and synthesized azoinitiators 
useful class of the radical polymerization initiators, especially functional initiators with e.g. hydroxyl end groups $[12,13]$. They are used in radical polymerization carried out both in solution and emulsion systems.

\section{Experimental}

\subsection{Materials for Azoinitiators Synthesis}

2,2'-azobisisobutyronitrile (AIBN) - from MerckSchuchardt - was purified by crystallization from methanol. The diols for the azoinitiators synthesis were prepared as follows: 1,4-butanediol (BD) from MerckSchuchardt was purified by distillation under reduced pressure, tri(oxyethylene)diol (TriOE) from Aldrich and oligo(oxyethylene)diol [OOE(400)] from Hoechst AG were dried to a constant mass under reduced pressure. Solvent - chloroform (analytically pure) from POCH Gliwice was used as received.

\subsection{Azoinitiators Synthesis and Characteristics}

Azoinitiators have been synthesized by the Pinner's reaction of 2,2'-azobisisobutyronitrile [2,2'-azobis (2methylpropionitrile)] with diols [14, 15], where AIBN first undergoes the oxidation to 2,2' -azobis (2-methylpropionic acid) and then reacts in condensation-esterification in the presence of diols. The Pinner's reaction stages are: protonation, nucleophilic addition and hydrolysis. The reaction substrates dissolved in chloroform are saturated with gaseous, anhydrous hydrogen chloride; its dissociation facilitates the protonation of the nitrile groups. The formed cations attached the diol molecules. During the next stage in the presence of water the hydrolysis reaction of ion $=\stackrel{\oplus}{\mathrm{NH}_{2}}$ takes place with saving the ester group and the ammonium chloride evolves. The detailed description of the azoinitiators preparation by means of the Pinner's reaction and the apparatus scheme are presented in the works $[15,16]$.

According to the same procedure, changing only the molar ratio of diol to AIBN, dependently on the reagents (Table 1), the following series of azoesters was prepared:

- monomeric, containing one azo-bond in the molecule and simultaneously ditelechelic - with two hydroxyl end groups:

AIB-BD - 2,2'-azobis(2-methyl-4-hydroxybutyl propionate),

AIB-Tri(OE) 2,2'-azobis[2-methyl- $\omega$-hydroxytri(oxyethylene) propionate],

- ditelechelic macro-azoinitiator with a larger number of azo-bonds, as the mix ture of mono- and dimeric azoesters:

AIB-OOE(400) 2,2'-azobis[2-methyl- $\omega$-hydroxyoligo(oxyethylene) propionate] (Fig. 2).
The presented compounds occur in various physical states at a room temperature - AIBN in a solid state, whereas AIB-BD, AIB-Tri(OE) and AIB-OOE(400) in a liquid state.

The determination of the synthesized azoesters chemical structure was enabled by a spectroscopic analysis using IR and UV-vis spectrophotometers, respectively, Specord M80 and M40 (Carl Zeiss Jena) with Medson software (Figs. 3 and 4).

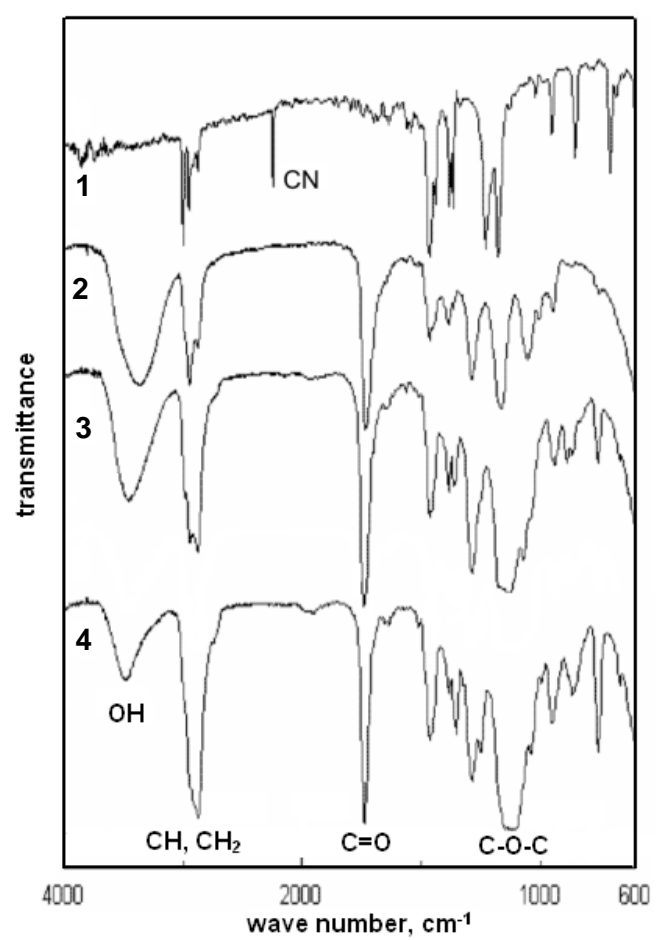

Fig. 3. IR spectra of investigated azoinitiators: AIBN (1), AIB-BD (2), AIB-Tri(OE) (3) and AIB-OOE(400) (4)

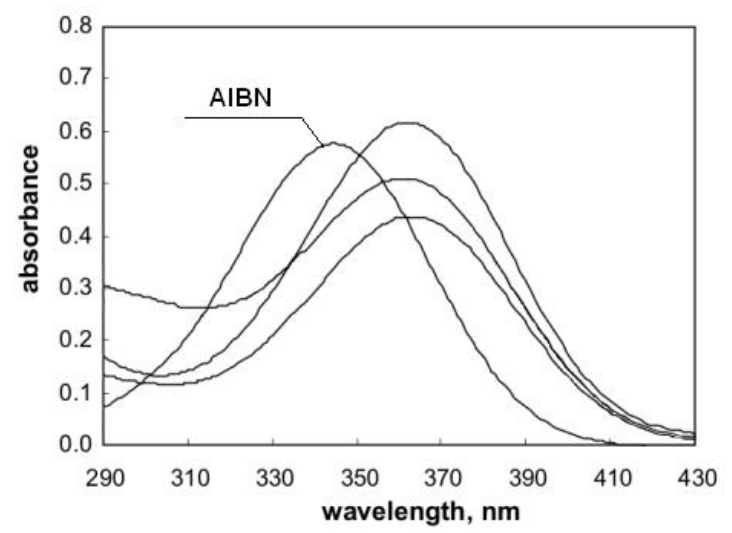

Fig. 4. UV-VIS spectra of azoinitiators

As can be seen in Fig. 3, the band at $2244 \mathrm{~cm}^{-1}$ characteristic for $\mathrm{CN}$ groups decays and the new absorption bands characteristic for ester group ( $-\mathrm{C}-\mathrm{O}-\mathrm{C}-$ ) and carbonyl group $(\mathrm{C}=\mathrm{O})$ appear at $1123 \mathrm{~cm}^{-1}$ and $1739 \mathrm{~cm}^{-1}$, respectively, 
in the spectrum of azoinitiator AIB-BD and the broader band in the range of $1084-1140 \mathrm{~cm}^{-1}$ characteristic for ether groups and at $1735 \mathrm{~cm}^{-1}$ for carbonyl groups in the spectra of AIBTri(OE) and AIB-OOE(400). Besides, the bands originated from hydroxyl group - $\mathrm{OH}$ and $\mathrm{C}-\mathrm{H}$ bonds in methyl and methylene groups in the range $2850-2900 \mathrm{~cm}^{-1}$ appear in the wave number range of $3200-3500 \mathrm{~cm}^{-1}$.

The UV-vis absorption spectra of azoinitiators confirm the presence of azo-bonds. For AIBN the characteristic symmetrical band occurs at the wave length of $\lambda_{\max }=344.6 \mathrm{~nm}$, while for AIB-BD, AIB-Tri(OE) and AIB-OOE(400) the maximum is shifted to the wave length of about $361 \mathrm{~nm}$ (Fig. 4).

\subsection{Synthesis of Acrylic Pressure-Sensitive Adhesives Using Azoinitiators}

\subsubsection{Materials}

The acrylate monomers 2-ethylhexyl acrylate, methyl acrylate and acrylic acid were purchased from BASF (Germany). AIBN was supplied by Degussa and other tested radical azoinitiators (Fig. 2) were synthesized in the Polymer Institute at Szczecin University of Technology.

\subsubsection{Polymerization process}

The basic solvent-borne acrylic PSA were synthesized using monomers mixture composed of 2-ethylhexyl acrylate
(60 wt \%), methyl acrylate (35 wt \%) and acrylic acid (5 wt \%) in the ethyl acetate at its boiling temperature $(350 \mathrm{~K})$ in the presence of AIBN and other azoinitiators with concentrations listed in Table 2 (wt \% in respect to monomers mixture). Polymerization process was carried out under specified conditions: $1 \mathrm{~h}$ dosage time, $5 \mathrm{~h}$ post-reaction time to reach $50 \mathrm{wt} \%$ of acrylic polymer content.

\subsubsection{Testing methods}

The viscosity of the synthesized solvent-borne acrylic pressure-sensitive adhesives containing AIBN and the azoinitiators was determined with a Rheomat RM 189 from Rheometric Scientific, with the spindle No 3 at 296 K.

The molecular weight studies were conducted in tetrahydrofurane with a liquid chromatograph LaChrom system: RI Detector L-7490 and LaChrom UV Detector L-7400 from Merck-Hitachi, equipped with a PLgel $10^{6} \AA$ column from Hewlett-Packard.

\section{Results and Discussion}

The azoinitiator type and concentration effect on viscosity, molecular weight and polydispersity of synthesized solvent-borne acrylic pressure-sensitive adhesives are shown in Table 2 and presented in Figs. 5-8.

As can be seen in Fig. 5 the highest viscosities of solvent-borne acrylic PSA have been observed for products

Viscosity, molecular weight and polydispersity of synthesized acrylic PSA

Table 2 in the presence of AIBN and functional azoinitiators

\begin{tabular}{|c|c|c|c|c|c|}
\hline \multicolumn{2}{|c|}{ Amount of azoinitiator } & \multirow{2}{*}{$\begin{array}{c}\text { PSA viscosity, } \\
\text { mPa } \cdot \mathrm{s}\end{array}$} & \multirow{2}{*}{$\bar{M}_{w}$} & \multirow{2}{*}{$\bar{M}_{n}$} & \multirow{2}{*}{$P_{d}=\frac{\bar{M}_{w}}{\bar{M}_{n}}$} \\
\hline wt $\%$ & mol & & & & \\
\hline \multicolumn{6}{|c|}{ 2,2'-azobisisobutyronitrile (AIBN) } \\
\hline 0.1 & 0.0003 & 5100 & 656000 & 182000 & 3.60 \\
\hline 0.3 & 0.0009 & 3300 & 405000 & 104000 & 3.89 \\
\hline 0.5 & 0.0015 & 1400 & 287000 & 66000 & 4.35 \\
\hline 0.8 & 0.0024 & 800 & 135000 & 26400 & 5.11 \\
\hline 1.0 & 0.0030 & 450 & 86000 & 13600 & 6.32 \\
\hline \multicolumn{6}{|c|}{ 2,2'-azobis[2-methyl- $\omega$-hydroxy-oligo(oxyethylene) propionate] [(AIB-OOE(400)] } \\
\hline 0.64 & 0.0003 & 6500 & 693000 & 195000 & 3.55 \\
\hline 1.92 & 0.0009 & 4600 & 489000 & 132000 & 3.70 \\
\hline 3.20 & 0.0015 & 2500 & 332000 & 79800 & 4.16 \\
\hline 5.12 & 0.0024 & 1200 & 210000 & 44100 & 4.76 \\
\hline 6.40 & 0.0030 & 760 & 111000 & 20000 & 5.55 \\
\hline \multicolumn{6}{|c|}{ 2,2'-azobis[2-methyl- $\omega$-hydroxy-tri(oxyethylene) propionate] [(AIB-Tri(OE)] } \\
\hline 0.26 & 0.0003 & 14600 & 814000 & 270000 & 3.01 \\
\hline 0.78 & 0.0009 & 10100 & 732000 & 220000 & 3.33 \\
\hline 1.30 & 0.0015 & 7600 & 692000 & 190000 & 3.64 \\
\hline 2.08 & 0.0024 & 5300 & 503000 & 125000 & 4.02 \\
\hline 2.60 & 0.0030 & 2600 & 365000 & 82400 & 4.43 \\
\hline \multicolumn{6}{|c|}{ 2,2'-azobis(2-methyl-4-hydroxybutyl propionate) (AIB-BD) } \\
\hline 0.2 & 0.0003 & 16000 & 856000 & 306000 & 2.80 \\
\hline 0.6 & 0.0009 & 12300 & 754000 & 245000 & 3.08 \\
\hline 1.0 & 0.0015 & 10000 & 701000 & 213000 & 3.29 \\
\hline 1.6 & 0.0024 & 7300 & 633000 & 168000 & 3.77 \\
\hline 2.0 & 0.0030 & 4100 & 435000 & 108000 & 4.03 \\
\hline
\end{tabular}




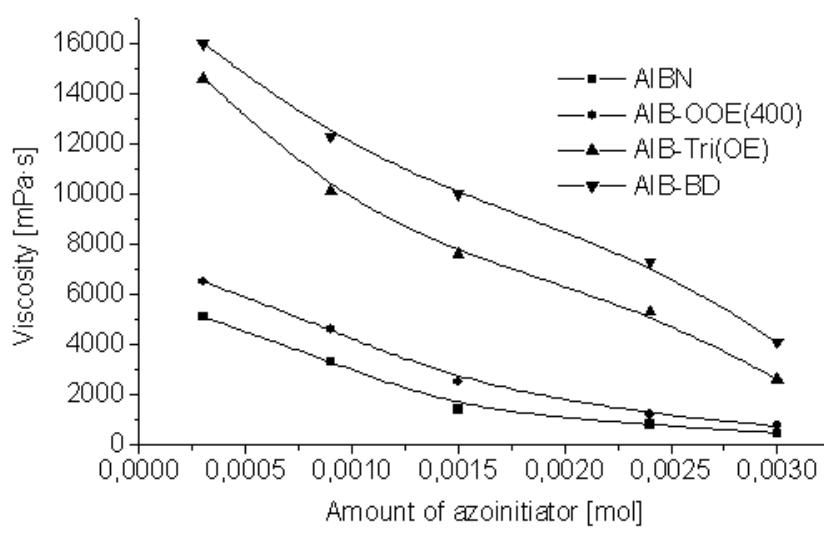

Fig. 5. Viscosity of acrylic PSA synthesized by the use of AIBN and azoesters

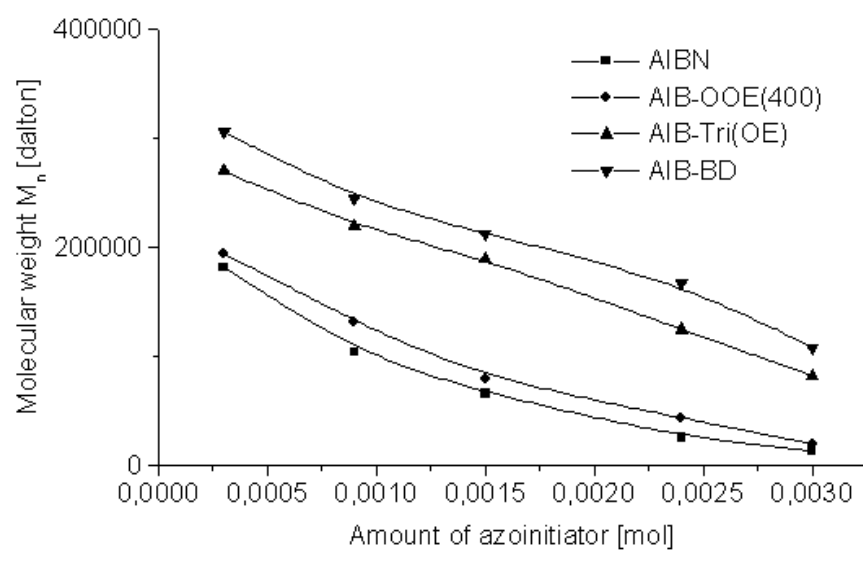

Fig. 7. Molecular weight $\bar{M}_{n}$ of acrylic PSA synthesized by the use of AIBN and azoesters

obtained in copolymerization initiated by azoesters: 2,2'azobis[2-methyl- $\omega$-hydroxy-tri(oxyethylene) propionate] [AIB-Tri(OE)] and 2,2'-azobis(2-methyl-4-hydroxybutyl propionate) (AIB-BD). The products synthesized in the presence of azoester 2,2' -azobis[2-methyl- $\omega$-hydroxyoligo(oxyethylene) propionate] [AIB-OOE(400)] have shown a similar viscosity using commercial available AIBN. So, the viscosity of synthesized acrylic PSA is very sensitive to the variations of azoinitiator type and concentration.

The great attention was attached to the weightaverage molecular weight (Fig. 6) and number-average molecular weight (Fig. 7) of synthesized acrylic PSA using AIBN and functional azoinitiators. As expected after evaluation of viscosity, the increase of the initiators concentration causes the decrease of their molecular weights. However, the azoesters AIB-Tri(OE) and AIB$\mathrm{BD}$ give the high level of molecular weight values to PSA and can be recommended instead of AIBN for radical polymerization of acrylate monomers.

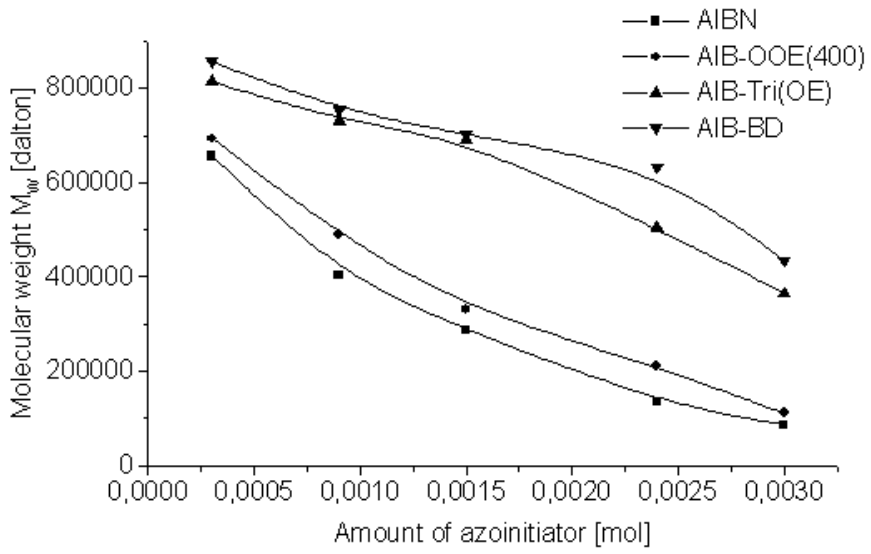

Fig. 6. Molecular weight $\bar{M}_{w}$ of acrylic PSA synthesized by the use of AIBN and azoesters

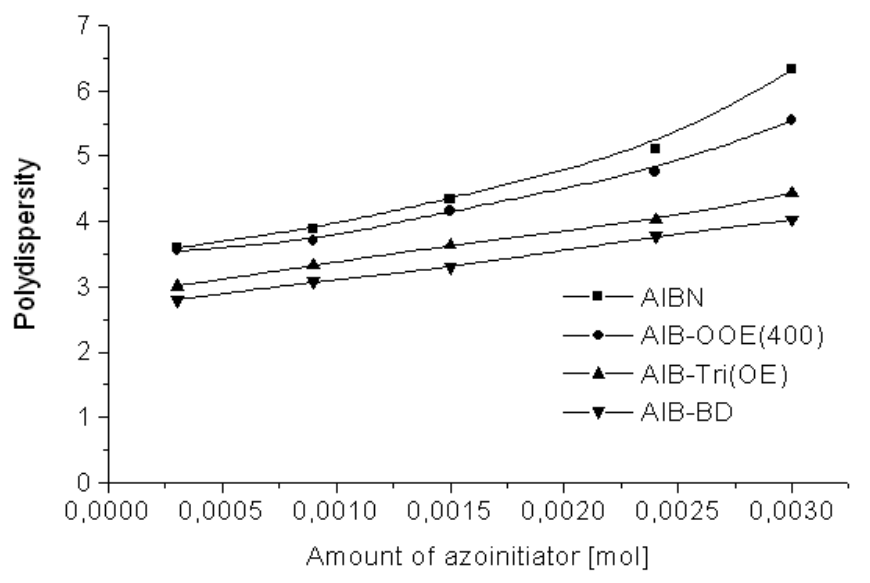

Fig. 8. Polydispersity of acrylic PSA synthesized by the use of AIBN and azoesters

The physicochemical and mechanical properties of PSAs such as tack (initial adhesion), peel adhesion (adhesion) and shear strength (cohesion) are determined in a high degree by their molecular weight distribution (polydispersity). Polydispersity can also affect the dispersion of the softening points of the linear, amorphous polymer. The molecular weight and polydispersity strongly influence the viscosity of polymers [17].

The polydispersity was tested in order to study the influence of investigated azoesters and AIBN on acrylic PSA physic-mechanical properties, significant for manufacture of technical and medical self-adhesive articles. All tested azoinitiators show very similar influence-run on the polymers polydispersity, however on different level. The acrylic PSA with low polydyspersity are characterized by high $\overline{\mathrm{M}}_{\mathrm{n}}$ and $\overline{\mathrm{M}}_{\mathrm{w}}$ values.

The high polydispersity means a very good tack and adhesion and in this case the best behaviour always guarantees AIBN. But the synthesis of cohesive acrylic PSA using 2,2'-azobis(2-methyl-4-hydroxybutyl propionate) (AIB-BD) will be advisable and justified. 


\section{Conclusions}

The functional azoinitiators can be perfectly used for the solvent polymerization process of various acrylate monomers. Different behaviour of synthesized azoesters as polymerization initiators compared to the commonly used AIBN is influenced by various lengths of hydrocarbonic chains, the presence of ether bonds, $\mathrm{OH}$ groups and their distance from azo-bonds [18]. From the applied initiators especially two azoesters AIB-BD and AIBOOE $(400)$ vary by the molecules size - the length of hydrocarbonic chains and the presence (in AIB-OOE(400)) of ethylene oxide blocks. The differences in the chemical structure of the azoinitiators influence the course of radical polymerization and consistently the products properties.

\section{References}

[1] Benedek I. (ed.): Developments in pressure-sensitive products, CRC Press, Boca Raton FL 2006.

[2] Czech Z.: Int. J. Adhes. Adhes., 2004, 24, 503.

[3] Czech Z.: Polym. Adv. Technol., 2004, 15, 539.

[4] Lin J. and Wen W.: Adhes. Age, 1985, 12, 22.

[5] Odian G.: Principles of polymerization, $3^{\text {rd }}$ Edn., Wiley, New York 1991.

[6] Matyjaszewski K. and Davis T. (eds.): Handbook of radical polymerization, Wiley - Interscience 2002.

[7] Matyjaszewski K.: XVI Ogolnopolskie Seminarium Naukowe - Postep w chemii i fizyce polimerow, Lodz, 2001.

[8] Czech Z., Butwin A., Herko E., Hefczyc B. and Zawadiak J.: eXPRESS Polym. Lett., 2008, 2, 277.

[9] Moad G. and Solomon D.: The chemistry of free radical polymerization, $1^{\text {st }}$ Edn. Elsevier Sci. Ltd. 1995.

[10] Buback M., Huckestein B., Kuchta F.-D. et al.: Macromol. Chem. Phys., 1994, 195, 2117.
[11] Sugiyama K., Ohga K. and Kikukawa K.: Makromol. Chem. Phys., 1994, 195, 1341.

[12] Onderko K., Pabin-Szafko B. and Szafko J.: Karbo, 2004, 49, 175.

[13] Wisniewska E. and Pabin-Szafko B.: e-Polymers 2007, 136. [14] Walz R., Bomer B. and Heitz W.: Makromol. Chem., 1997, 178, 2527.

[15] Pabin-Szafko B., Wisniewska E. and Szafko J.: Polimery, 2005, 50, 271.

[16] Pabin-Szafko B., Wisniewska E. and Szafko J.: Ekoplast, 2002, 21-22, 47.

[17] Benedek I.: Pressure-sensitive design, theoretical aspects. VSP, Leiden Boston 2006.

[18] Wisniewska E. and Pabin-Szafko B.: Polimery, 2007, 52, 562.

\section{СЕЛЕКТИВНІ РАДИКАЛЬНІ АЗОІНІЩІАТОРИ У СИНТЕЗІ ОБМЕЖЕНО РОЗЧИННИХ «ПРЕСОВАНИХ» АКРИЛОВИХ КЛЕЇВ}

\begin{abstract}
Анотація. Показана можливість використання функиійних азоініціаторів: 2,2'-азобіс(2-метил-4гідроксибутил пропіонату), 2,2'-азобіс[2-метилтри(оксиетилен) пропіонату] та 2,2'-азобіс[2-метил- $\omega$ гідрокси-оліго(оксиетилен) пропіонату] в радикальній полімеризації 2-етилгексилакрилату, метилакрилату $i$ метакрилової кислоти в органічному розчиннику етилацетаті для одержання обмежено розчинних акрилових клеїв, здатних склеюватись при надавлюванні. Визначено в'язкість, молекулярну масу і полідисперсність одержаних клеїв та проведений порівняльний аналіз з продуктом полімеризачї, ініційованоӥ звичайним азоініціатором 2,2'-азобісізобутиронітрилу.
\end{abstract}

Ключові слова: функиійний азоініціатор, акрилові мономери, радикальна полімеризація, акрилові клеї. 